\title{
The effect of temperature of the root medium and of the growing point of the shoot on growth, water content and sugar content of maize leaves
}

\author{
A. Kleinendorst and R. Brouwer \\ Institute for Biological and Chemical Research on Field Crops and Herbage (IBS), \\ Wageningen, the Netherlands \\ Department of Plant Physiological Research, Agricultural University, Wageningen, \\ the Netherlands
}

Received 17 April 1970

\section{Summary}

In experiments where the temperature of the root medium and of the growing point of the leaves were varied independently leaf growth rate and leaf water content of maize plants were continuously recorded. The effect of root temperature on leaf growth was mediated by the water balance in the plant and was subject to osmotic adaptation, which proceeded faster and was more complete at favourable growing point temperatures.

\section{Introduction}

Among others Beauchamp and Lathwell (1967) and Grobbelaar (1963) studied the effect of root temperature on growth of maize. Since lowering the root temperature exhibited a direct and reversible reduction in leaf growth rate Brouwer (1964) ascribed the growth reduction to a developing water stress as a result of reduced water permeability of the root tissue. Nevertheless water content of the leaves of maize plants grown for a number of days on nutrient solutions kept at various temperatures differed only slightly (Grobbelaar, 1963), whereas the growth reduction continued.

Brouwer and Locher (in prep.) found that the rate of leaf appearance up to the 8th leaf was determined by the temperature of the root medium. In these early stages of development the growing point of the plant is rather close to the soil, and its temperature follows more or less the temperature of the root medium (Beauchamp and Torrance, 1969).

It seems highly desirable, therefore, to vary root temperature and growing point temperature independently.

\section{Materials and methods}

Maize seedlings were grown on aerated Hoagland solution in a climate room of $20^{\circ} \mathrm{C}$, using an 18-hour light period per 24 hours and a light intensity of about 70,000 ergs $\mathrm{cm}^{-2} \mathrm{sec}^{-1}$. 


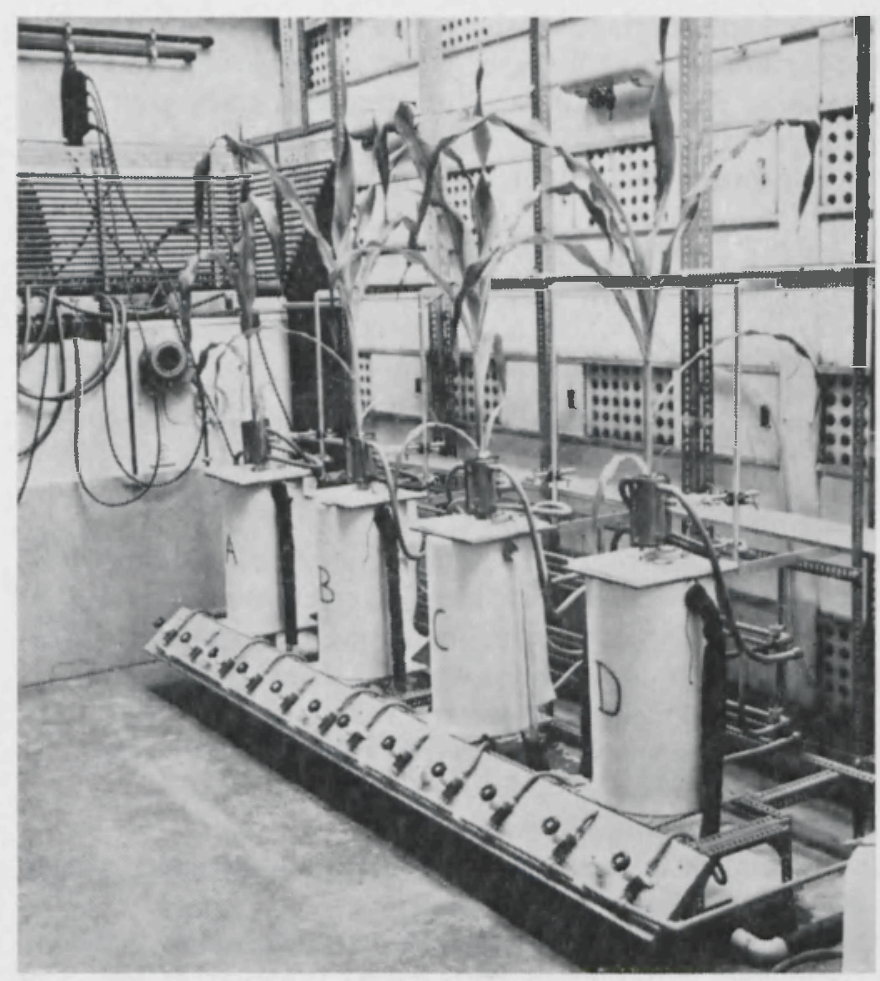

Fig. I Photograph of the set-up to grow maize plants with controlled root and growing point temperalures.

At the 8th leaf stage (8th leaf just emerging from the surrounding sheaths) the plants were transferred to the experiment room where root and growing point temperature could be varied independently (Fig. 1 and 2). Via thin wire thread, leaf elongation could make a weight turn a resistance in an electric circuit. The output was recorded and linearly related to leaf elongation. In this way a leaf elongation of $10 \mathrm{~cm}$ a day

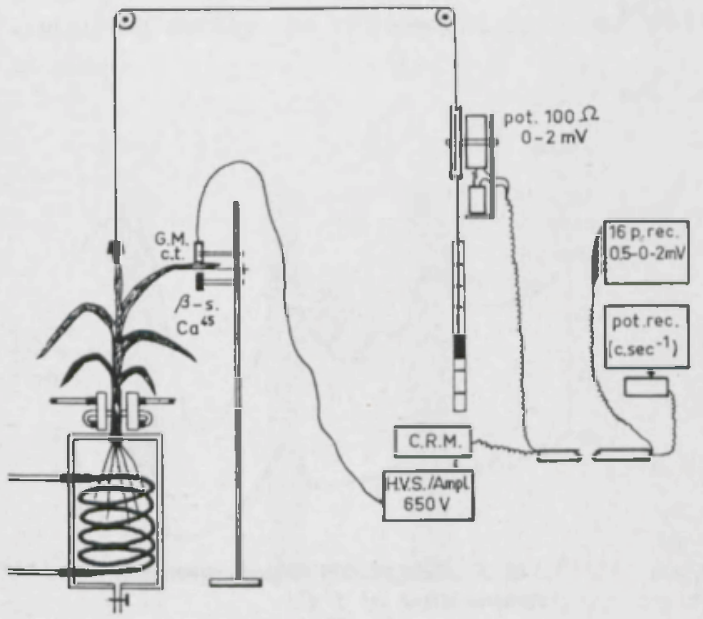

Fig. 2 A schematic drawing of the set-up. G.M.c.t. = Geiger-Muller count tube; $\beta$-s. $\mathrm{Ca}^{15}=$ beta source; C.R.M. = count rate meter. 
could still accurately be subdivided into periods as short as a quarter of an hour.

Changes in mass per unit leaf area due to changes in water content were measured by a $\beta$ gauge. $10 \mu \mathrm{c} \mathrm{Ca}{ }^{45}$ mounted in the top of a small perspex rod was placed under the leaf. A GM tube was mounted at the opposite side of the leaf. With a voltage supply amplifier and a count rate meter the output was continuously recorded on a line recorder.

It was not necessary to correct the recordings for leaf shrinkage, because with the small changes in water content obtained in these experiments shrinkage in area was less than $1 \%$.

\section{Results}

Instantaneous responses to changing of the root temperature

Brouwer (1964) showed that transference from a root temperature of $20^{\circ} \mathrm{C}$ to $5^{\circ} \mathrm{C}$ or $10^{\circ} \mathrm{C}$ instantaneously reduced leaf growth in Phaseolus. Transference back to $20^{\circ} \mathrm{C}$ was followed by an equally instantaneous recovery. In maize the reactions were identical and obviously resembled the effects of temporary water stress as described by Acevedo et al. (1969) using the same crop. Continuous recording showed that rate of leaf growth and water content were changing simultaneously (Fig. 3).

Response to changing the temperature of the growing point

The growth reaction was in principle the same as reported in the former section (Fig. 4). The water content of the leaf tissue, however, did not respond to lowering the temperature of the growing point whatsoever. It is assumed therefore that the cause of the growth reduction is completely different in both cases. Whereas at low root

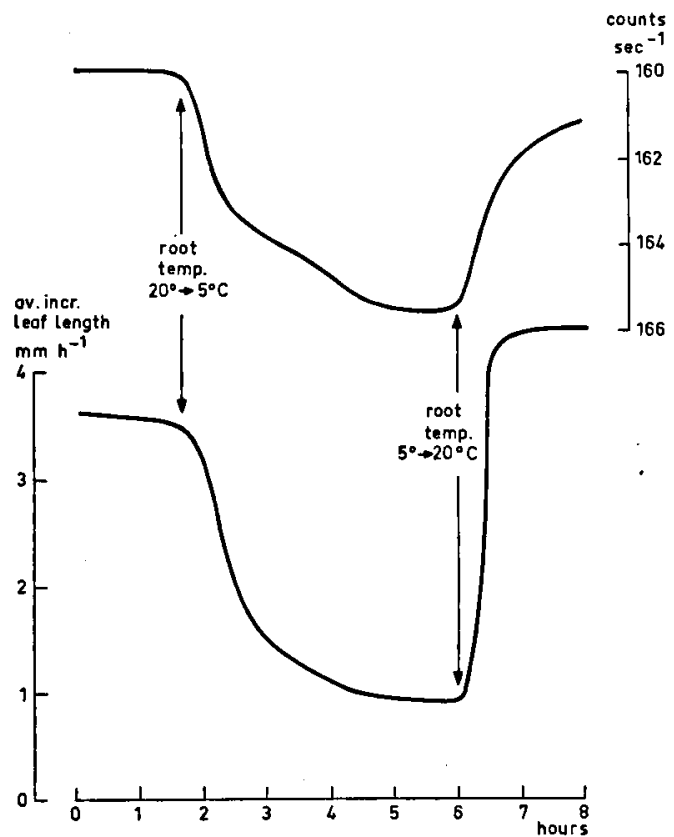

Fig. 3 Temporary application of a root temperature of $5^{\circ} \mathrm{C}$. 


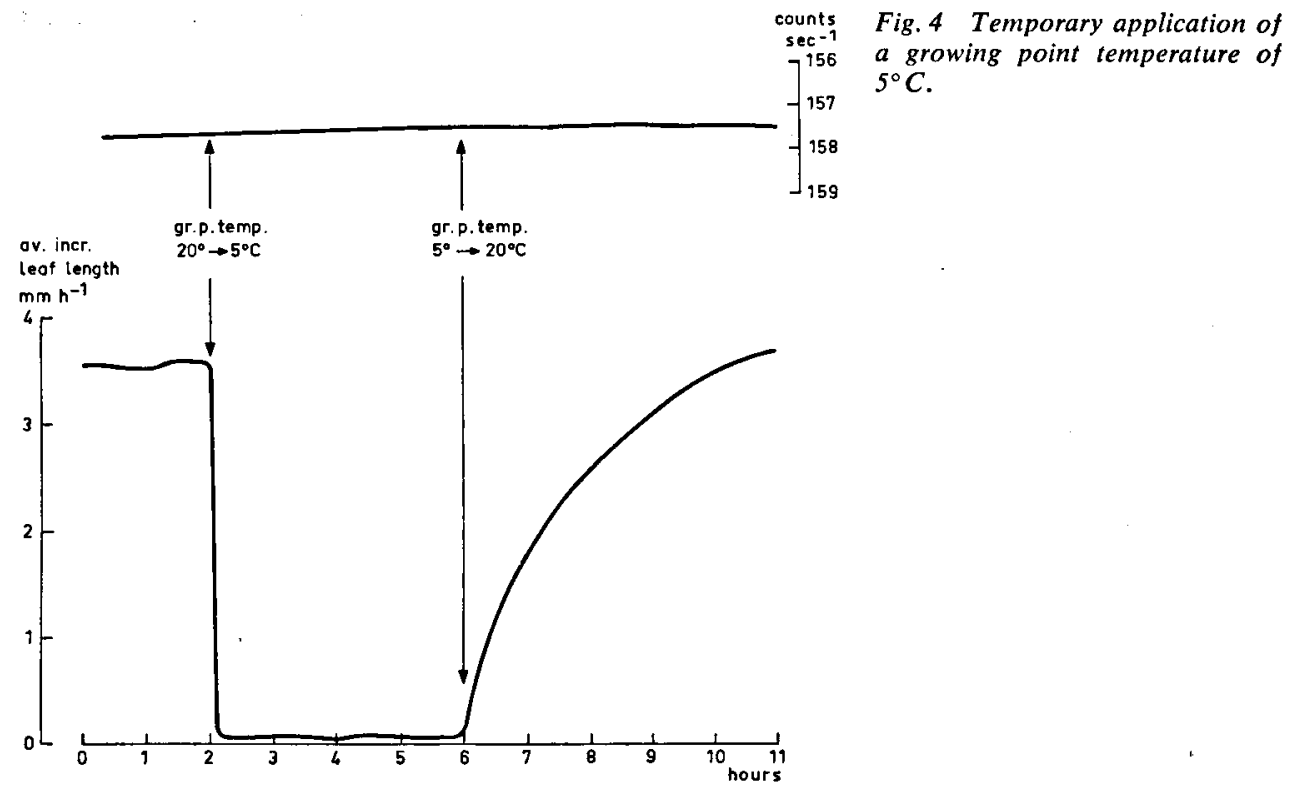

temperatures the induced water stress was most likely the limiting factor for leaf growth, at a low growing point temperature, which means a low temperature of the whole growing region of the leaves, various physiological activities leading to growth were reduced.

\section{Adaptation to low root temperatures}

It was found that the effect of a low root temperature on growth was more serious in the light period than in the dark. This is further evidence for involvement of the water balance of the plant. In most cases both growth rate and water content recovered gradually during the treatment. Sometimes the first signs of recovery could already be observed from the middle of the first light period (Fig. 5). This recovery continued during the subsequent days but was never completed until after three days at least.

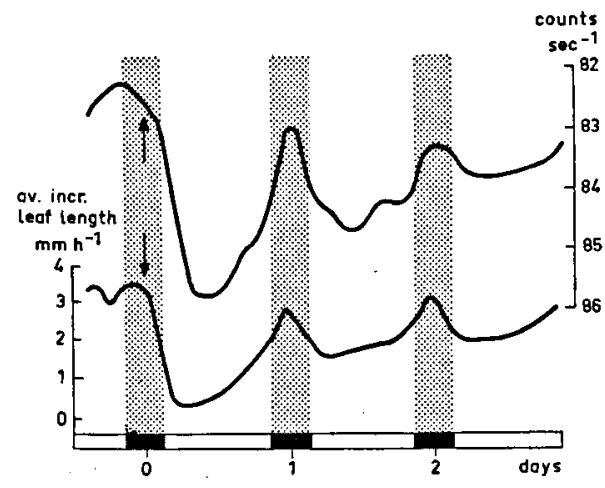

Fig. 5 Response of growth rate and water content to a change in root temperature from $20^{\circ} \mathrm{C}$ to $5^{\circ} \mathrm{C}$ (start indicated by arrow). 


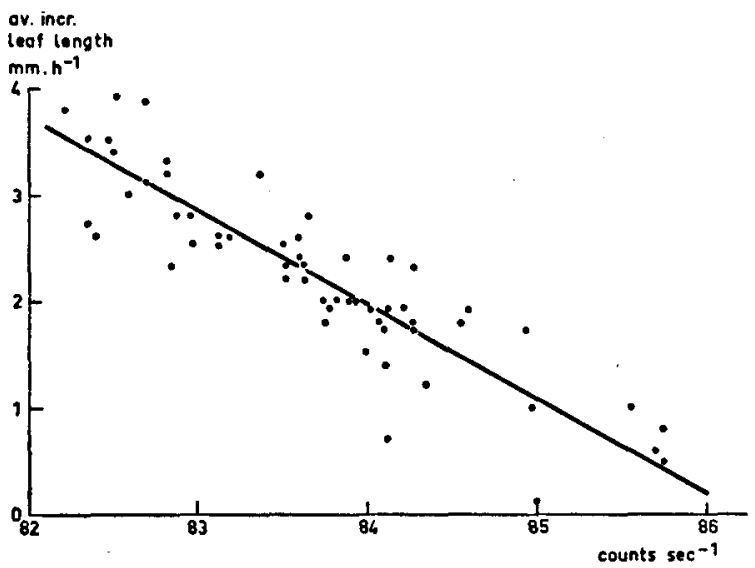

Fig. 6 Relation between leaf growth rate and leaf water content.

It is comparable with the effects on bean plants (Brouwer, 1964) where after transference to a low root temperature the leaves regained turgidity in a couple of days after initial wilting.

The recovery of leaf growth rate and water content in maize paralleled each other rather closely (Fig. 6) and it is assumed that this correlation is causal.

No adaptation to a low growing point temperature

The immediate effect on growth was the same for low growing point temperatures and low root temperatures. In contrast the light-dark differences were much smaller, no influence on the water content was observed and no recovery of the growth rate was found during a two day treatment at low growing point temperature (Fig. 7). The reduction in growth rate rather increased with time. This indicates that the nature of the growth limitation changed somewhat, possibly from cell elongation to cell division.

Interaction between root temperature and growing point temperature

The response of leaf elongation to root temperatures of $5^{\circ}, 15^{\circ}$ and $25^{\circ} \mathrm{C}$ each com-

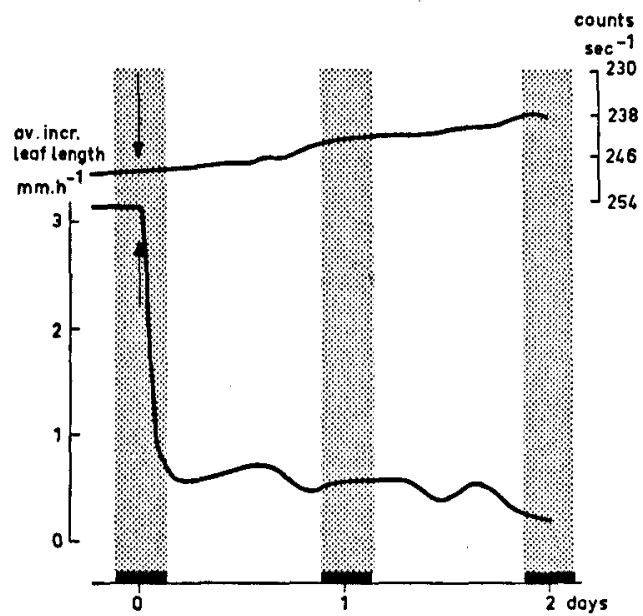

Fig. 7 Response of growth rate and water content to a change in growing point temperature from $20^{\circ} \mathrm{C}$ to $5^{\circ} \mathrm{C}$ (start indicated by arrow). 


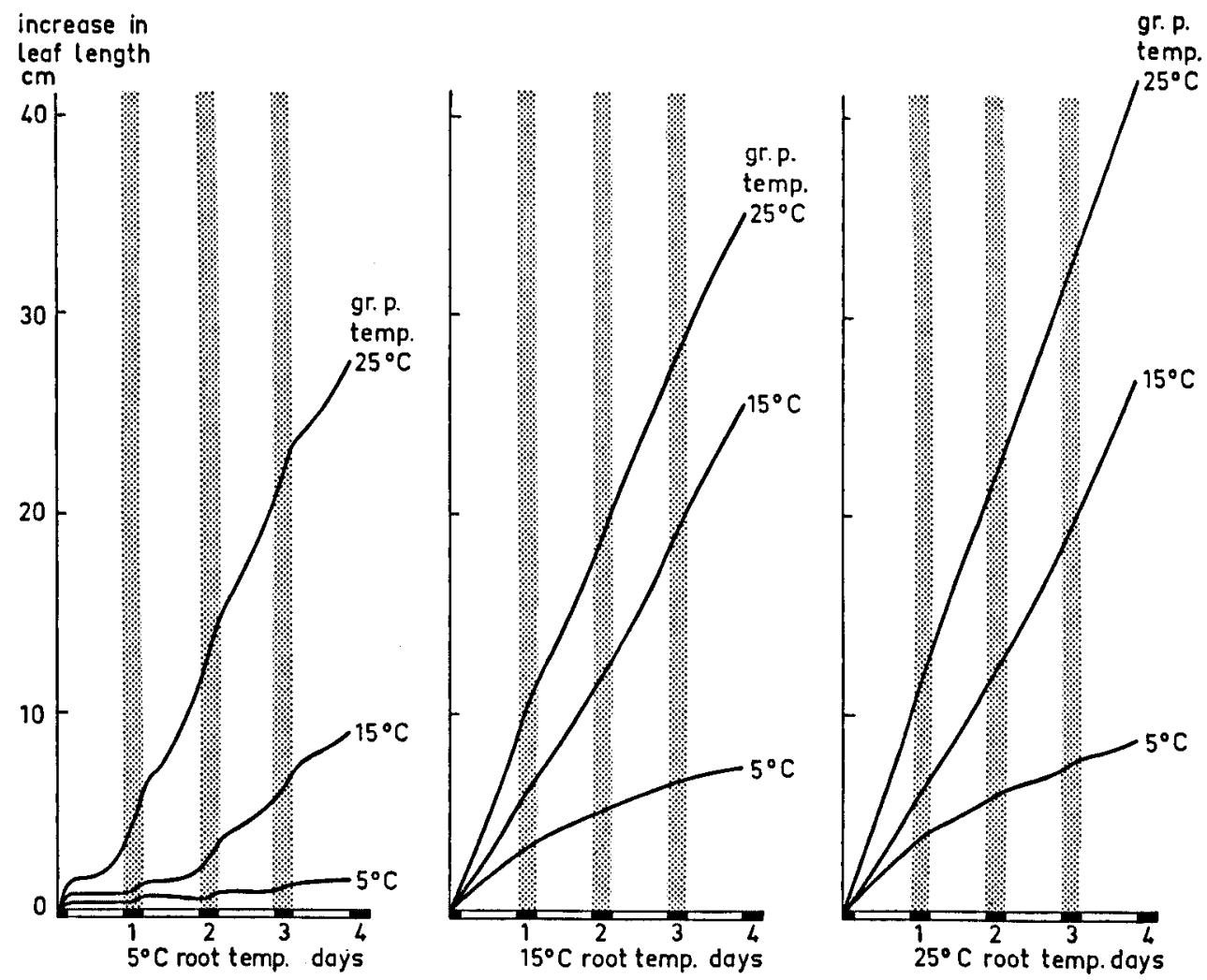

Fig. 8 Interaction between the influence of root temperature and growing point temperature on leaf growth.

bined with growing point temperatures of $5^{\circ}, 15^{\circ}$ and $25^{\circ} \mathrm{C}$ in a four-day experiment is shown in Fig. 8.

Total growth responded to both factors, the growing point temperature being somewhat more effective. Adaptation to the low root temperature of $5^{\circ} \mathrm{C}$ as measured in recovery of leaf growth during treatment was faster and more complete, the higher the growing point temperature. Obviously the osmotic adaptation of the growing region was favoured by a high temperature. In all cases differences between growth rates in light and dark occurred (Fig. 9). Incidentally dark growth rates at a root temperature of $5^{\circ} \mathrm{C}$ and a growing point temperature of $25^{\circ} \mathrm{C}$ exceeded those at a $25^{\circ} \mathrm{C}$ treatment of roots and growing point.

Leaf growth, water content and soluble carbohydrate content

It was shown by Grobbelaar (1963) that after transference of maize plants from a root temperature of $20^{\circ} \mathrm{C}$ to suboptimal and supraoptimal root temperatures the dry matter content of roots and shoots of maize plants gradually increased. At root temperatures of $5^{\circ}$ and $10^{\circ} \mathrm{C}$ it was more than doubled. At the same time the soluble sugar content in the dry matter increased even more.

It seems likely that in our experiments at least part of the recovery of leaf growth during the treatment at low root temperatures was due to an increased osmotic value 


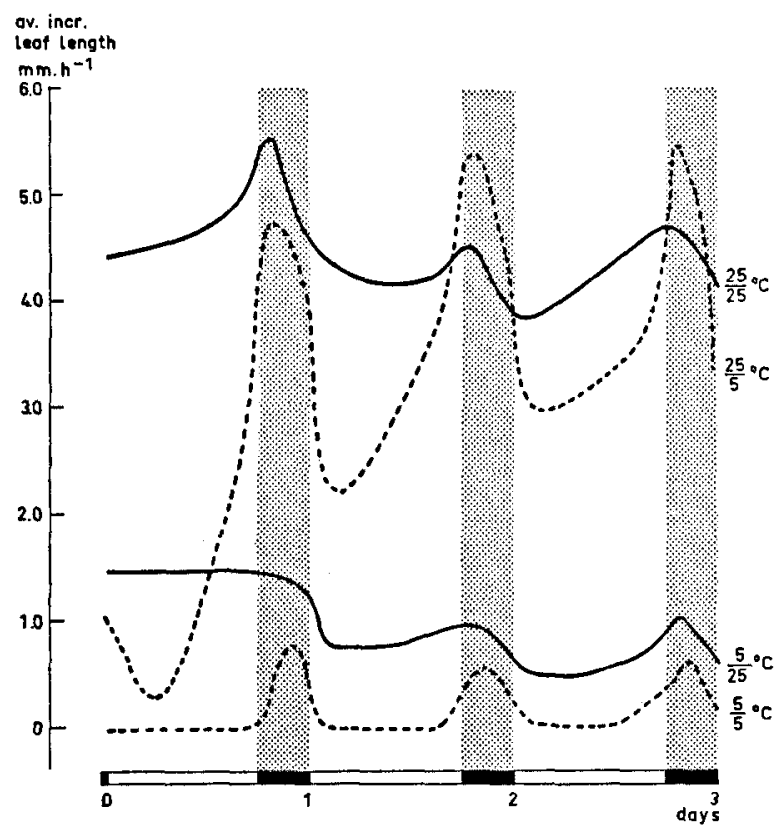

Fig. 9 The effect of root temperature (denominator) and growing point temperature (numerator) on leaf growth rate in light and darkness.

of the cell sap to that cell elongation could be resumed even at a high suction tension. Fig. 10 shows the reactions in plants which were transferred from a root temperature of $20^{\circ}$ to $5^{\circ} \mathrm{C}$ in the middle of the dark period. At the onset of light leaf growth stopped, water content decreased, and sugar content remained constant. Recovery started about 6 hours after. From that time the sugar content gradually increased and was followed by an increase in water content and a resumption of growth. In the next dark period water content and growth rate rose further as a result of the reduced transpiration. Sugar content decreased but was at a much higher level than the night before.

\section{Discussion}

The data presented above suggest that after lowering the temperature of the roots water stresses are induced in the shoot tissue including the growing region of the leaves as a result of the reduced water permeability of the root tissue. The roots do not regain their permeability so that the suction tension in the tissue remains high. However the osmotic value of the cell sap gradually increases so that at the same high suction tension turgidity is recovered $(S=O-T)$ and growth is resumed. The increase in osmotic concentration is dependent on the temperature of the growing region itself. Hence the effect of a low root temperature is less severe when at the same time the temperature of the growing region is maintained at a favourable level. The growth activities in this region are mainly dependent on the temperature in situ so that a favourable root temperature cannot compensate for a low temperature of the growing region. In addition this effect is due to the temperature influence on biochemical reactions which in contrast to water stress are not subject to ready adaptations. The lasting effect of low root temperatures as described by Grobbelaar (1963) 


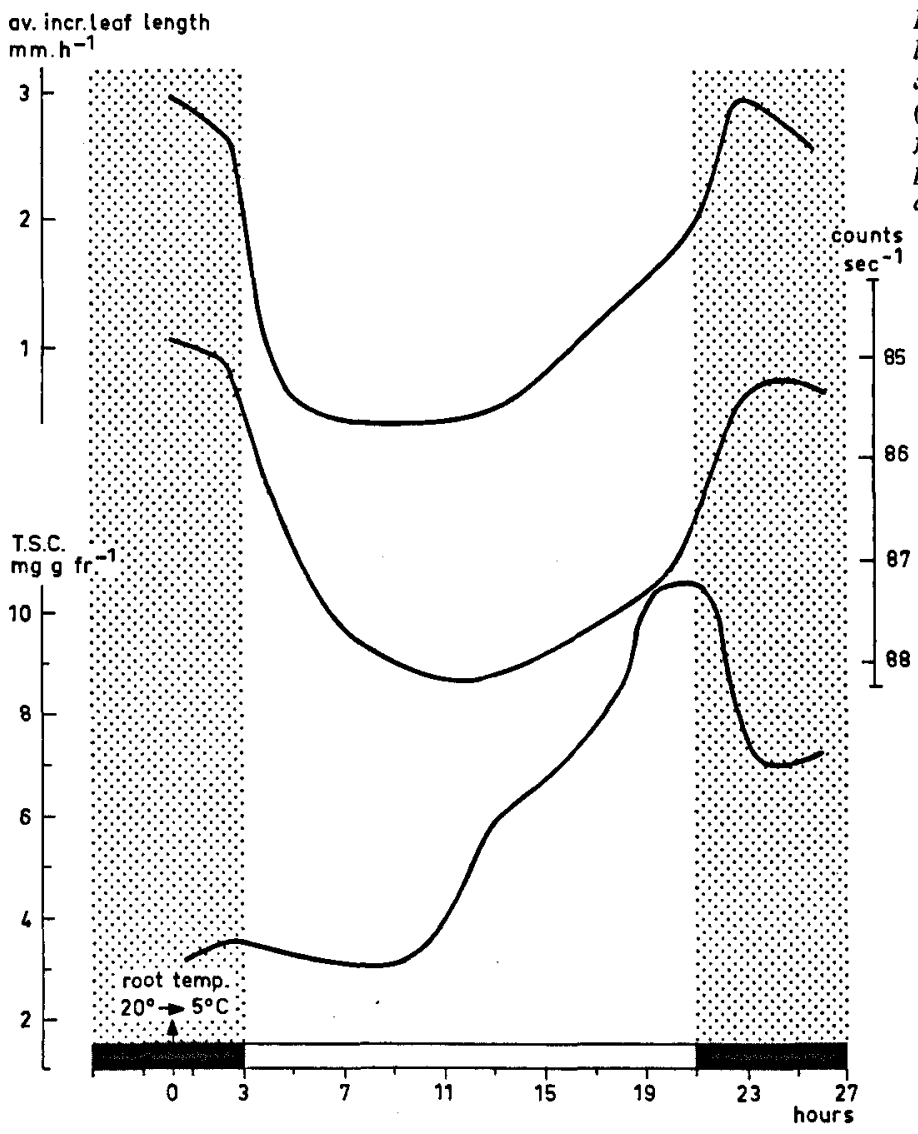

Fig. 10 Time course of change in leaf growth rate, leaf water content and soluble carbohydrate content ( $m g$ per $g$ fresh weight) when transferring a plant from a root temperature of $20^{\circ} \mathrm{C}$ to $5^{\circ} \mathrm{C}$ during the dark period.

and others, where adaptations have not been found, are due to the fact that with normal planting an important part of the growing region is also subjected to the root temperature.

It should be emphasized that more quantitative data on the enhancement of the osmotic value are greatly needed. It might be that even with complete recovery of the turgidity growth could be reduced due to effects on the hydrature of the cytoplasm (Walter, 1955).

\section{Acknowledgments}

Many thanks are due to Mrs J. G. Boersma-Rinkema for her assistance in carrying out the experiments.

\section{References}

Acevedo Edmundo, Theodore C. Hsiao \& D. W. Henderson, 1969. Extreme dependence of leaf elongation in Zea Mays - as measured with a highly sensitive method - on its water status. Pl. Physiol. 44 (suppl.) 23 (abstracts of the annual section meetings). 
Beauchamp, E. G. and D. J. Lathwell, 1967. Root-zone temperature effects on the early development of maize. Pl. Soil 26: 224-234.

Beauchamp, E. G. and J. K. Torrance, 1969. Temperature gradients within young maize plant stalks as influenced by aerial and root zone temperatures. Pl. Soil 30: 241-251.

Brouwer, R., 1964. Responses of bean plants to root temperatures. I. Root temperatures and growth in the vegetative stage. Jaarb. IBS 1964: 11-22.

Grobbelaar, W. P., 1963. Responses of young maize plants to root temperatures. Meded. LandbHogesch. Wageningen 63 (5) 1-71.

Walter, H., 1955. The water economy and hydrature of plants. Ann. Rev. Pl. Physiol. 6: 239-252. 